Article

\title{
The Relationship between Poor Pulmonary Function and Irregular Pulse in the Elderly: Findings from a Nationwide Cross-Sectional Survey in Korea
}

\author{
Sun Hwa Kim ${ }^{1}$, Yonggu Lee ${ }^{2} \mathbb{C}$, Seon Young Hwang ${ }^{3}$, Jinho Shin ${ }^{4}$, Chun Ki Kim ${ }^{5}$ and \\ Jin-Kyu Park 4,*(D) \\ 1 Department of Nursing, Hanyang University Medical Center, Seoul 04763, Korea; 79ssunhwa@gmail.com \\ 2 Division of Cardiology, Hanyang University Guri Hospital, Guri 11900, Korea; hmedi97@naver.com \\ 3 College of Nursing, Hanyang University, Seoul 04763, Korea; seon9772@hanyang.ac.kr \\ 4 Division of Cardiology, Department of Internal Medicine, College of Medicine, Hanyang University Medical \\ Center, Seoul 04763, Korea; jhs2003@hanyang.ac.kr \\ 5 Department of Medicine, Hanyang University College of Medicine, Seoul 04763, Korea; \\ chunkikim@hanyang.ac.kr \\ * Correspondence: cardiohy@hanyang.ac.kr; Tel.: +82-2-2290-8307
}

Received: 14 July 2020; Accepted: 30 August 2020; Published: 1 September 2020

\begin{abstract}
Arrhythmia may be caused by reduced pulmonary function, and pulse palpation is a useful screening method for the early detection of cardiac arrhythmia. The aim of this study was to investigate the association between reduced pulmonary function and abnormal findings on pulse palpation in 2347 subjects aged $\geq 65$ years using data from a nationwide survey. Pulse palpation was initially performed for $15 \mathrm{~s}$ and, if felt to be abnormal, it was performed again for $60 \mathrm{~s}$. The prevalence of irregular pulse (IP) determined by the 60-second palpation was $61(2.6 \%)$. The mean age of subjects with an IP was 73.0 (95\% CI 71.7-74.3) years, and 45.8\% were male. After adjustment for covariates, forced vital capacity (FVC)/predicted FVC, forced expiratory volume in one second $\left(\mathrm{FEV}_{1}\right) /$ predicted $\mathrm{FEV}_{1}$, and the lowest $\mathrm{FEV}_{1}$ remained significant risk factors for IP. A restrictive or obstructive spirometry pattern was also an independent risk factor for IP. In summary, an IP is more prevalent when pulmonary function is reduced in the elderly, in whom careful pulse palpation may be necessary for the early detection of arrhythmia.
\end{abstract}

Keywords: arrhythmia; atrial fibrillation; physical examination; pulmonary function test; pulse rate

\section{Introduction}

Some cardiac arrhythmias do not cause any symptoms and may first be discovered only incidentally during a routine examination. Some patients are unaware of the presence of arrhythmia, even when it is chronic. Therefore, early detection and treatment of arrhythmias are critical for minimizing associated complications. One of the most common arrhythmias in the elderly is atrial fibrillation (AF). This condition increases the risk of stroke five-fold and the risk of cardiac failure three-fold, leading to an increase in the mortality rate [1-3]. Patients usually recognize the onset of paroxysmal AF due to feeling palpitations with a sensation of a rapid heartbeat [4]. An irregular pulse (IP) can also be a sign of an arrhythmia [5].

An IP on physical examination is not a rare finding in primary care settings. Pulse palpation is a useful screening method for the early detection of cardiac arrhythmias $[5,6]$ and is routinely included in physical examinations by a clinical nurse. Opportunistic screening for early AF detection by pulse palpation in subjects 65 years of age or older is recommended by the European Society of Cardiology guidelines [7]. This recommendation highlights the importance of appropriate and timely examination 
of the elderly for the early detection and prevention of stroke and heart disease. Systematic population screening is useful for identifying individuals with AF, but the use of electrocardiograms (ECGs) to screen for AF may be expensive and time-consuming [8]. The Screening for Atrial Fibrillation in the Elderly (SAFE) study concluded that opportunistic screening, such as pulse palpation and optional ECG, is the most appropriate screening method for those with IP [9]. Firzmaurice et al. also reported that pulse palpation is a cost-effective approach [10].

The heart and lungs have highly related hemodynamics; patients suffering from chronic obstructive pulmonary disease (COPD) are often found to have arrhythmias (including AF). In cases of COPD with insufficient pulmonary function, deterioration of gas composition, and pulmonary hypertension may result in elevated atrial pressure and altered electrophysiological properties of atrial tissue and can trigger ectopic beats and supraventricular tachycardia [11,12]. In addition, it has previously been reported that a low forced expiratory volume in one second $\left(\mathrm{FEV}_{1}\right)$ is related to an increased risk of $\mathrm{AF}$ [13]. The risk of AF was 1.8 times higher for those with an $\mathrm{FEV}_{1}$ between $60 \%$ and $80 \%$, and reduced lung function has been reported to be an independent predictor of AF [14]. Therefore, subjects with reduced lung function may benefit from more judicious screening for cardiac arrhythmia.

While pulse palpation is a useful screening method for the early detection of cardiac arrhythmias and has a high sensitivity for atrial fibrillation $[5,6,10]$, the utility of pulse palpation or the prevalence of IP in subjects with reduced pulmonary function relative to those with normal pulmonary function is not yet known. Therefore, we aimed to examine the relationship between pulmonary function and irregular pulse (IP) in people aged 65 or older.

\section{Materials and Methods}

\subsection{Study Design}

A cross-sectional descriptive survey design using a secondary analysis of national data was adopted for this study to identify the relationship between reduced pulmonary function and IP.

\subsection{Setting and Sample}

The present study was performed using nationally representative data from the $5^{\text {th }}$ Korea National Health and Nutrition Examination Survey (KNHANES V), a government-approved statistical survey performed between 2010 and 2012 by the Korean Centers for Disease Control and Prevention [15]. The survey was released and made available for download from the KNHANES website (https: $/ / \mathrm{knhanes.cdc.go.kr/)} \mathrm{after} \mathrm{its} \mathrm{approval} \mathrm{for} \mathrm{use.} \mathrm{A} \mathrm{rolling} \mathrm{sampling} \mathrm{design} \mathrm{for} \mathrm{the} \mathrm{survey} \mathrm{was} \mathrm{employed,}$ which involved a stratified, complex, multi-stage, probability-clustered survey on a sample representing the community-dwelling civilian population in South Korea. The survey was distributed to 11,400 households in 568 national districts. The enumeration districts were created by separating the country into 11 regions. These regions were subdivided into 26 regional layers based on population composition by age. The survey comprised three components: (1) a nutrition survey for dietary assessment, (2) a health examination survey on common cardiovascular diseases and chronic diseases such as cancer, pulmonary disease, arthritis, and so on, and (3) a health interview survey on general health conditions and health-related lifestyle.

Of all subjects aged $\geq 65$ years in the KNHANES database, 2347 subjects who completed the health examination survey and had spirometry data were included in this study.

\subsection{Measurements}

\subsubsection{General Characteristics}

A self-administered questionnaire was used to evaluate the history of cigarette smoking (current smoker, ex-smoker, or non-smoker), consumption of alcohol, and level of physical activity (walking, moderate, or strenuous activity), and the data were collected by interviewers. Those who smoked 
fewer than 100 cigarettes in their lifetime were considered non-smokers, while those who smoked more than 100 cigarettes were classified as ex- or current smokers. The frequency of alcohol consumption was divided into four categories based on the average number of drinks in the one-year period before the survey (on average 1 or less per month, 2-4 times per month, 2-3 times per week, or 4 or more times per week). The average amount of alcohol intake in a single session was also classified into four categories, i.e., none, $1-4$ servings, $5-9$ servings, or $\geq 10$ servings per session.

Physical activity was classified into 3 categories: walking regularly for $30 \mathrm{~min}$ or longer in indoor or outdoor at least 5 times a week was categorized as 'Walking', exercising for 30 min or longer by carrying a light item at least 3 times a week was categorized as 'Moderate activity', and activities such as climbing, running, fast biking, and carrying heavy objects for $20 \mathrm{~min}$ or longer at least 3 times per week were categorized as 'Strenuous activity' means.

\subsubsection{Physiological Data}

Body weight, height, and waist circumference were measured by well-trained examiners. Body weight was recorded to the nearest $0.1 \mathrm{~kg}$ using a calibrated balance-beam scale (Giant-150N; Hana Co. Ltd., Seoul, Korea). A portable stadiometer (850-2060 mm; Seriter, Bismarck, ND, USA) was used to measure height to the nearest $1 \mathrm{~mm}$. Waist circumference was measured and recorded to the nearest $0.1 \mathrm{~cm}$ in a horizontal plane at the midpoint between the iliac crest and the costal margin at the end of a normal expiration. Body mass index (BMI) was estimated as body weight $(\mathrm{kg})$ divided by height squared $\left(\mathrm{m}^{2}\right)$.

Blood samples were taken using a venipuncture during the health examination after an overnight fast of at least $8 \mathrm{~h}$. Total cholesterol, serum glucose, triglycerides, creatinine, and high-density lipoprotein (HDL) cholesterol were enzymatically assessed. Blood pressure and pulse rate were measured by a nurse on the professional checkup team within the Korean Centers for Disease Control and Prevention. Blood pressure (BP) was measured three times using mercury sphygmomanometers (Baumanometer; Baum, Copiague, NY, USA) while subjects sat quietly after a 5-minute rest. The final $\mathrm{BP}$ value was calculated by taking the average value of the second and third BP measurements.

\subsubsection{Pulse Palpation}

The radial pulse was palpated initially for $15 \mathrm{~s}$ after the subjects had rested for five minutes in a seated position. If the pulse was felt to be not completely normal, e.g., irregular, slow (less than 15 beats), or fast (more than 26 beats), the pulse palpation was performed again for $60 \mathrm{~s}$. Subjects were finally considered to have an "IP" if there were variations in the rhythm of pulses in the radial artery during 60-second palpation.

\subsubsection{Spirometry Measurement}

Spirometry was performed using a dry rolling-seal spirometry device (Vmax series Sensor Medics 2130; Sensor Medics, Anaheim, CA, USA) that was operated by specially trained technicians who complied with the pulmonary function test (PFT) guidelines by the American Thoracic Society and European Respiratory Society [16]. Participants with $\mathrm{FEV}_{1} /$ forced vital capacity (FVC) of $<0.7$ were considered to have COPD. The study only used spirometry results that contained two or more acceptable curves that met the reproducibility criteria [16].

\subsection{Data Analysis}

Statistical analyses were carried out using the Statistical Package for the Social Sciences (SPSS, IBM, Armonk, NY, USA) program, version 18.0. The sample weights were incorporated, and the analyses were adjusted for the survey's complex sample design. We weighted the survey samples in all of the analyses to generate the estimations that represented the Korean non-institutionalized civilian population. More details regarding how the adjustment was performed are available in a previous study [15]. Continuous variables are represented by mean values with confidence intervals (CIs) of 95\%, and 
categorical variables are represented by frequencies and percentages. The chi-square test was employed to analyze the categorical variables. The differences in the mean values were evaluated by Student's t-tests. A multivariate binary logistic regression analysis was performed to assess the independent relationship between the spirometry results or the history of COPD and IP. Each of 6 parameters of spirometry including FVC (categorical), FVC/predicted FVC (pFVC) (continuous), FVC/pFVC $\geq 80 \%$ (binary), $\mathrm{FEV}_{1}$ (categorical), $\mathrm{FEV}_{1}$ /predicted $\mathrm{FEV}_{1}$ ( $\mathrm{pFEV}_{1}$ ) (continuous), and the interpretation of the spirometry results (categorical; normal versus restrictive versus obstructive) were evaluated in the multivariate models. We first assessed the strength of associations between IP and potential confounding variables, including age, sex, BMI, waist circumference, alcohol consumption, chronic diseases (hypertension, diabetes, congestive heart failure, angina, previous myocardial infarction, hypercholesterolemia, hypertriglyceridemia and hypo-HDL cholesterolemia), smoking status, thyroid disease, medications (antihypertensive, antidiabetic, and lipid-lowering drugs), and physical activity, using univariate binary logistic models. Of these variables, those with $p<0.1$ were selected and included in the multivariate binary logistic models as covariates. Then, multivariate binary logistic models for the presence of IP were generated with each parameter of the spirometry results or the history of COPD and the selected covariates. FVC and FEV 1 were evenly divided into 4 levels based on their respective quartile values, and the adjusted odds ratio (aOR) and 95\% CI for each level of the variables were estimated against their respective highest quartile level as the reference. A two-tailed $p$-value of less than 0.05 was considered statistically significant.

\section{Results}

\subsection{General Characteristics}

The general characteristics of all subjects are shown in Table 1. Among the 2347 subjects, 61 (2.6\%) were judged to have an IP (hereafter referred to as the IP group). Figure 1 shows the prevalence of IP stratified by age. The highest frequency of IP (3.9\%) was seen in those older than 80 years of age, while the prevalence of IP tended to increase with age $(p=0.090)$. Smoking status was not significantly different between the two groups. However, there was a significant difference in alcohol consumption frequencies between the IP group and those with a regular pulse (hereafter referred to as the RP group) ( $p=0.022)$. There was no significant difference in the degree of physical activity between the two groups.

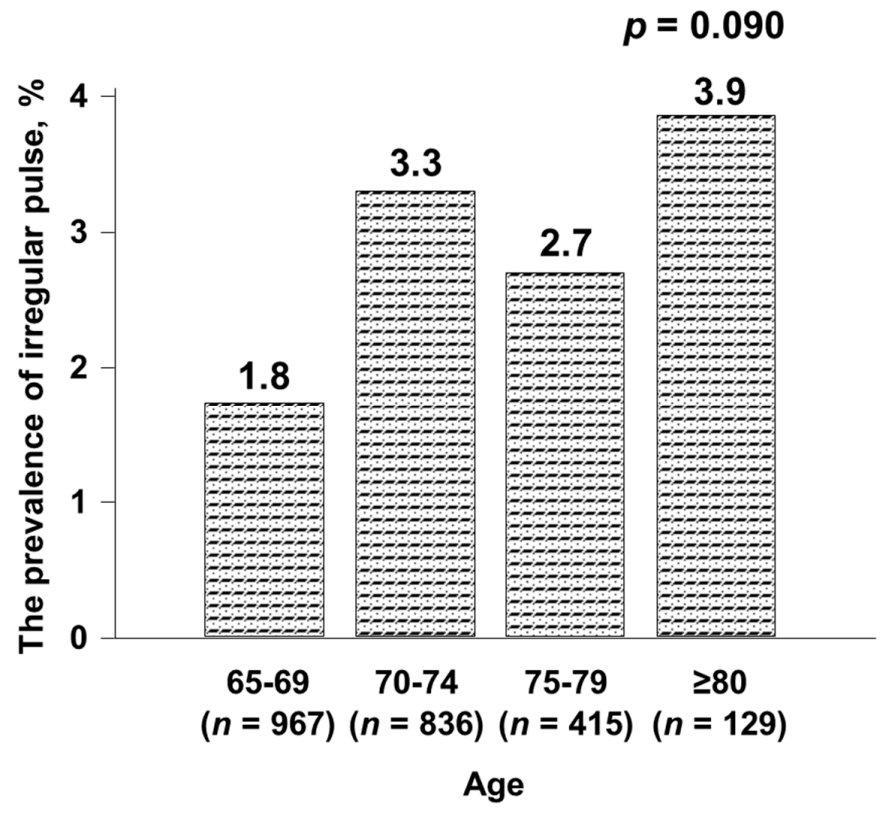

Figure 1. Prevalence of irregular pulse in the general population $\geq 65$ years old. 
Table 1. General characteristics.

\begin{tabular}{|c|c|c|c|}
\hline \multirow[t]{2}{*}{ Characteristics } & $\begin{array}{l}\text { Irregular Pulse } \\
\qquad(n=61)\end{array}$ & $\begin{array}{l}\text { Regular Pulse } \\
\quad(n=2286)\end{array}$ & \multirow[t]{2}{*}{$p$} \\
\hline & $n(\%)$ & $n(\%)$ & \\
\hline Age (yr) & $73.0(71.7-74.3)$ & $72.2(71.9-72.5)$ & 0.214 \\
\hline Age $\geq 75$ years & $16(32.2)$ & $528(31.0)$ & 0.881 \\
\hline Sex (male) & $29(45.8)$ & 979 (40.5) & 0.493 \\
\hline \multicolumn{4}{|l|}{ Chronic disease } \\
\hline Hypertension & $45(75.6)$ & $1384(62.6)$ & 0.088 \\
\hline Diabetes mellitus & $15(28.1)$ & $407(18.9)$ & 0.154 \\
\hline History of COPD & $2(2.0)$ & $19(1.0)$ & 0.373 \\
\hline Congestive heart failure & $2(3.5)$ & $47(2.5)$ & 0.660 \\
\hline Angina & $2(1.6)$ & $112(4.5)$ & 0.126 \\
\hline Previous stroke & $4(6.2)$ & $68(3.1)$ & 0.200 \\
\hline \multicolumn{4}{|l|}{ Hyperlipidemia } \\
\hline Hypercholesterolemia & $8(13.5)$ & $502(22.8)$ & 0.150 \\
\hline Hypertriglyceridemia & $5(9.4)$ & $331(18.2)$ & 0.151 \\
\hline Hypo-HDL cholesterolemia & $15(31.9)$ & $614(30.3)$ & 0.855 \\
\hline Thyroid disease & $0(0.0)$ & $112(5.1)$ & 0.155 \\
\hline \multicolumn{4}{|l|}{ Medication use, n (\%) } \\
\hline Antihypertensive drugs & $37(58.5)$ & $1152(51.2)$ & 0.477 \\
\hline Antidiabetic drugs (including insulin) & $11(21.4)$ & $366(16.0)$ & 0.379 \\
\hline Lipid-lowering drugs & $4(5.7)$ & $327(12.8)$ & 0.136 \\
\hline Cigarette smoking status & & & 0.703 \\
\hline Current smoker & $8(10.1)$ & $254(11.7)$ & \\
\hline Ex-smoker & $17(32.3)$ & $627(26.8)$ & \\
\hline Non-smoker & $34(57.6)$ & $1367(61.5)$ & \\
\hline Alcohol consumption frequency & & & 0.022 \\
\hline$\leq 1$ time/month & $44(74.6)$ & $1590(70.8)$ & \\
\hline 2-4 times/month & $2(3.4)$ & $284(12.7)$ & \\
\hline 2-3 times/week & $3(5.1)$ & $184(8.2)$ & \\
\hline$\geq 4$ times/week & $10(16.9)$ & $187(8.3)$ & \\
\hline Amount of alcohol & & & 0.611 \\
\hline None & $32(57.9)$ & $1051(49.0)$ & \\
\hline $1-4$ servings & $20(34.6)$ & $977(42.0)$ & \\
\hline $5-9$ servings & $6(5.8)$ & $185(7.6)$ & \\
\hline$\geq 10$ servings & $1(1.7)$ & $34(1.4)$ & \\
\hline \multicolumn{4}{|l|}{ Physical activity } \\
\hline Walking & $21(27.6)$ & $885(38.1)$ & 0.202 \\
\hline Moderate activity & $2(6.6)$ & $207(9.1)$ & 0.640 \\
\hline Strenuous activity & $3(4.0)$ & $204(8.2)$ & 0.205 \\
\hline
\end{tabular}

COPD: chronic obstructive pulmonary disease, HDL: high-density lipoprotein. Continuous variables are presented as the mean (95\% confidence interval), and dichotomous variables are presented as $\mathrm{n}(\%)$.

\subsection{Clinical Data Comparisons}

None of the clinical characteristics or laboratory findings listed in Table 2 were statistically significantly different between the IP and RP groups, although the difference in the waist circumference approached the significance level with a $p$ value of 0.065 ( 87.6 for the IP groups versus 84.9 for the RP group). The difference in the heart rate was associated with the second-lowest $p$ value (66.0 for the IP group versus 69.2 for the RP group, $p=0.085)$, although it was not significant. 
Table 2. Clinical data.

\begin{tabular}{cccc}
\hline Characteristics & $\begin{array}{c}\text { Irregular Pulse } \\
(\boldsymbol{n}=\mathbf{6 1})\end{array}$ & $\begin{array}{c}\text { Regular Pulse } \\
(\boldsymbol{n}=\mathbf{2 2 8 6})\end{array}$ & $p$ \\
\hline Body mass index, $\mathrm{kg} / \mathrm{m}^{2}$ & $24.8(23.9-25.8)$ & $24.2(24.0-24.4)$ & 0.168 \\
Waist circumference, $\mathrm{cm}$ & $87.6(84.7-90.5)$ & $84.9(84.2-85.5)$ & 0.065 \\
Blood pressure, $\mathrm{mmHg}$ & & & \\
Systolic & $130.8(125.8-135.9)$ & $130.2(129.3-131.1)$ & 0.811 \\
Diastolic & $72.1(68.5-75.8)$ & $74.3(73.8-74.9)$ & 0.235 \\
Heart rate, $\mathrm{bpm}$ & $66.0(62.4-69.6)$ & $69.2(68.6-69.8)$ & 0.085 \\
Pulse pressure, $\mathrm{mmHg}$ & $58.7(54.4-62.9)$ & $55.9(55.2-56.6)$ & 0.193 \\
White blood cell count, $\times 10^{3} / \mathrm{mm}^{3}$ & $6.3(5.6-7.1)$ & $6.1(6.0-6.3)$ & 0.616 \\
Fasting glucose, $\mathrm{mg} / \mathrm{dL}$ & $104.7(98.4-110.9)$ & $102.7(101.6-103.9)$ & 0.546 \\
eGFR, mL/min/1.73 m ${ }^{2}$ & $76.3(72.7-79.9)$ & $78.9(77.7-80.1)$ & 0.165 \\
Total cholesterol, $\mathrm{mg} / \mathrm{dL}$ & $185.7(174.4-197.0)$ & $193.0(190.9-195.1)$ & 0.208 \\
HDL-C, $\mathrm{mg} / \mathrm{dL}$ & $46.8(43.5-50.1)$ & $46.6(46.0-47.2)$ & 0.875 \\
Triglycerides, $\mathrm{mg} / \mathrm{dL}$ & $125.6(106.7-144.6)$ & $141.0(136.7-145.3)$ & 0.117 \\
\hline
\end{tabular}

eGFR: estimated glomerular filtration rate, HDL-C: high-density lipoprotein cholesterol. Continuous variables are presented as the mean $(95 \% \mathrm{CI})$.

\subsection{Pulmonary Function Test and Irregular Pulse}

FVC/pFVC was significantly lower $(85.9 \%$ versus $90.6 \%)(p=0.005)$, and the prevalence of patients with $\mathrm{FVC} / \mathrm{pFVC}<80 \%$ was higher $(42.7 \%$ versus $19.3 \%)(p<0.001)$ in the IP group (Table 3$)$. However, there were no differences in the mean $\mathrm{FEV}_{1} / \mathrm{FVC}$ values or the prevalence of $\mathrm{FEV}_{1} / \mathrm{FVC}<0.7$ between the two groups. $\mathrm{FEV}_{1}$ was reduced (2.03 versus 2.14) $(p=0.040)$, and $\mathrm{FEV}_{1} / \mathrm{pFEV}_{1}$ was lower $(88.7 \%$ versus $93.3 \%)(p=0.027)$ in the IP group. Based on the interpretation of the PFT guidelines [16], subjects in the IP group more frequently showed restrictive $(22.4 \%$ versus $12.4 \%)$ and obstructive patterns $(37.5 \%$ versus $29.9 \%)$ and less frequently showed a normal pattern ( $40.1 \%$ versus $57.7 \%)$ compared to the RP group $(p=0.037)$.

Table 3. Spirometry data.

\begin{tabular}{|c|c|c|c|}
\hline Characteristics & $\begin{array}{l}\text { Irregular Pulse } \\
\quad(n=61)\end{array}$ & $\begin{array}{l}\text { Regular Pulse } \\
\quad(n=2286)\end{array}$ & $p$ \\
\hline FVC, L & $2.84(2.67-3.01)$ & $2.95(2.91-2.99)$ & 0.208 \\
\hline Quartile 1 (1.25-2.439) & $20(36.5)$ & $562(27.6)$ & 0.210 \\
\hline Quartile 2 (2.44-2.899) & $12(21.6)$ & $586(26.0)$ & \\
\hline Quartile 3 (2.90-3.529) & $21(30.5)$ & $559(23.8)$ & \\
\hline Quartile 4 (3.53-5.46) & $8(11.4)$ & $579(22.6)$ & \\
\hline FVC/predicted FVC, \% & $85.9(82.6-89.2)$ & $90.6(89.9-91.2)$ & 0.005 \\
\hline FVC/predicted FVC, $n(\%)$ & & & $<0.001$ \\
\hline$\geq 80 \%$ & $36(57.3)$ & $1837(80.7)$ & \\
\hline$<80 \%$ & $25(42.7)$ & $449(19.3)$ & \\
\hline $\mathrm{FEV}_{1} / \mathrm{FVC}$ & $0.72(0.70-0.75)$ & $0.73(0.73-0.74)$ & 0.656 \\
\hline $\mathrm{FEV}_{1} / \mathrm{FVC}, \mathrm{n}(\%)$ & & & 0.293 \\
\hline$\geq 0.7$ & $42(62.5)$ & $1636(70.1)$ & \\
\hline$<0.7$ & $19(37.5)$ & $650(29.9)$ & \\
\hline $\mathrm{FEV}_{1}, \mathrm{~L}$ & $2.03(1.93-2.13)$ & $2.14(2.11-2.17)$ & 0.040 \\
\hline Quartile 1 (0.74-1.82) & $17(33.3)$ & $563(28.2)$ & 0.122 \\
\hline Quartile 2 (1.83-2.14) & $19(35.2)$ & $565(26.1)$ & \\
\hline Quartile 3 (2.15-2.53) & $17(23.0)$ & $587(23.9)$ & \\
\hline Quartile 4 (2.54-3.99) & $8(8.5)$ & $571(21.8)$ & \\
\hline $\mathrm{FEV}_{1} /$ predicted $\mathrm{FEV}_{1}, \%$ & $88.7(84.8-92.7)$ & $93.3(92.4-94.2)$ & 0.027 \\
\hline Interpretation, $n(\%)$ & & & 0.037 \\
\hline Normal & $27(40.1)$ & $1334(57.7)$ & \\
\hline Restrictive & $15(22.4)$ & $302(12.4)$ & \\
\hline Obstructive & $19(37.5)$ & $650(29.9)$ & \\
\hline
\end{tabular}

FVC: forced vital capacity, $\mathrm{FEV}_{1}$ : forced expiratory volume in $1 \mathrm{~s}$. Continuous variables are presented as the mean ( $95 \%$ confidence interval), and dichotomous variables are presented as $n(\%)$. 


\subsection{The Effects of Reduced Pulmonary Function on IP}

FVC/pFVC $<80 \%$ was associated with IP (aOR $=2.68,95 \%$ CI: $1.50-4.80, p=0.001)$ after adjustment for covariates (Table 4). The subjects with lower $\mathrm{FEV}_{1}$ were more likely to have an IP compared with those with higher $\mathrm{FEV}_{1}$. FVC/pFVC and $\mathrm{FEV}_{1} / \mathrm{pFEV}_{1}$ were also inversely associated with IP (FVC/pFVC: aOR = 0.976, 95\% CI: 0.956-0.997, $p=0.023 ; \mathrm{FEV}_{1} / \mathrm{pFEV}_{1}: \mathrm{aOR}=0.986,95 \%$ CI: 0.973-0.999, $p=0.040$, respectively). Subjects with a restrictive or obstructive pattern had a significantly higher risk of IP than those with normal spirometry results (aOR $=1.95,95 \% \mathrm{CI}: 1.02-3.72, p=0.043$ ).

Table 4. Univariate and multivariate logistic regression analysis of pulmonary function for irregular pulse.

\begin{tabular}{|c|c|c|c|c|c|c|}
\hline \multirow{2}{*}{ Characteristics } & \multicolumn{3}{|c|}{ Univariate Logistic Models } & \multicolumn{3}{|c|}{ Multivariate Logistic Models } \\
\hline & $\begin{array}{c}\text { Unadjusted } \\
\text { OR }\end{array}$ & $95 \% \mathrm{CI}$ & $p$ & $\begin{array}{c}\text { Adjusted } \\
\mathrm{OR}^{+}\end{array}$ & $95 \% \mathrm{CI}$ & $p$ \\
\hline \multicolumn{7}{|l|}{ FVC, $\mathrm{L}$} \\
\hline Quartile 1 (1.25-2.43) & 2.62 & $1.04-6.57$ & 0.041 & 2.57 & $0.96-6.88$ & 0.061 \\
\hline Quartile 2 (2.44-2.89) & 1.64 & $0.55-4.91$ & 0.378 & 1.65 & $0.51-5.36$ & 0.404 \\
\hline Quartile 3 (2.90-3.52) & 2.53 & $0.94-6.82$ & 0.066 & 2.41 & $0.89-6.51$ & 0.082 \\
\hline Quartile 4 (3.53-5.46) & 1 & & & 1 & & \\
\hline FVC/predicted FVC, \% & 0.971 & $0.952-0.991$ & 0.005 & 0.976 & $0.956-0.997$ & 0.023 \\
\hline $\begin{array}{c}\text { FVC/predicted FVC }< \\
80 \%\end{array}$ & 3.11 & $1.73-5.61$ & $<0.001$ & 2.68 & $1.50-4.80$ & 0.001 \\
\hline \multicolumn{7}{|l|}{ FEV1, L } \\
\hline Quartile 1 (0.74-1.82) & 3.04 & $1.15-8.06$ & 0.025 & 3.09 & $1.02-9.37$ & 0.047 \\
\hline Quartile 2 (1.83-2.14) & 3.47 & $1.30-9.23$ & 0.013 & 3.55 & $1.24-10.13$ & 0.018 \\
\hline Quartile 3 (2.15-2.53) & 2.47 & $0.97-6.30$ & 0.059 & 2.44 & $0.90-6.59$ & 0.079 \\
\hline Quartile 4 (2.54-3.99) & 1 & & & 1 & & \\
\hline \multicolumn{7}{|l|}{ Interpretation } \\
\hline Normal & 1 & & & 1 & & \\
\hline Restrictive & 2.61 & $1.22-5.58$ & 0.014 & 2.31 & $1.01-5.27$ & 0.047 \\
\hline Obstructive & 1.81 & $0.88-3.70$ & 0.105 & 1.86 & $0.89-3.85$ & 0.097 \\
\hline Restrictive or obstructive & 2.04 & $1.09-3.83$ & 0.026 & 1.95 & $1.02-3.72$ & 0.043 \\
\hline History of COPD & 2.14 & $0.47-9.64$ & 0.468 & 2.56 & $0.57-11.60$ & 0.221 \\
\hline
\end{tabular}

\section{Discussion}

Pulse palpation and optional ECG for those with an IP could help identify the associated arrhythmia, especially AF, which is the most beneficial diagnosis for the early prevention of stroke in asymptomatic and undiagnosed elderly subjects. Inpatient measurement of vital signs, such as pulse palpation, is usually performed by nurses or physician assistants. It would be important for those performing pulse palpation to be aware of the value of IP in detecting new AF and preventing stroke in an early and timely manner. The present study showed that the lowest quartile of FEV 1 , $\mathrm{FVC} / \mathrm{pFVC}<80 \%$, and a restrictive or obstructive pattern based upon spirometry interpretation were significant risk factors of IP. Therefore, clinical nurses should pay particular attention to patients with more severely decreased pulmonary function or those already diagnosed with COPD or restrictive lung disease when performing pulse palpation. In contrast to inpatients who are carefully monitored by nurses, elderly community dwellers do not commonly have the opportunity to have their pulse checked by a professional on a daily or even weekly basis. Fortunately, it has been reported that a smartphone can be used to check for an IP at home without visiting a hospital [17,18]. Wearable devices such as a smartwatch are also now able to evaluate heart rhythms or irregular pulses with 
an improving accuracy [19]. This is particularly promising for elderly subjects because information technology applications will enable them to self-monitor for an IP at home without the aid of medical staff. Elderly people who are not accustomed to new technology, such as smartphones, could be assisted by family members. The appropriate application of such technology will enhance the timely detection of AF, even in elderly community members who are not hospitalized, especially those with reduced pulmonary function.

Reduced FEV1 and obstructive pulmonary disease are associated with a higher incidence of AF. The Atherosclerosis Risk in Communities (ARIC) study reported that impaired pulmonary function was correlated with higher AF incidence [20], and the Malmö Preventive Project found that impaired pulmonary function was an independent predictor of AF [21]. Therefore, people with impaired pulmonary function are part of an at-risk population that would benefit from more careful screening for AF. Alcohol consumption is also associated with AF. Recently, Kim et al. reported that frequent drinking per week is an important risk factor for AF using a Korean nationwide population-based study [22]. Our study showed similar findings—-that an IP had significantly more participants with alcohol consumption more than 4 times per week. While the diagnosis of AF requires rhythm documentation using an ECG, the ECG is not a cost-effective, first-step screening tool. On the other hand, pulse palpation is reported to be a simple, noninvasive, first-step screening tool to guide ECG diagnostics for cardiac arrhythmias with a high sensitivity [5,23] and has been considered the evidence-based method of choice for screening for arrhythmia among individuals aged $\geq 65$ by the European Society of Cardiology [7]. However, the American Heart Association/American College of Cardiology/Heart Rhythm Society (AHA/ACC/HRS) 2014 guidelines only mention pulse palpation as physical examination [1], and the AHA/ACC/HRS 2019 guidelines only focus on device detection [24]. For opportunistic screening, pulse palpation would be an especially useful method in older adults who had a risk factor for irregular pulse, such as poor pulmonary function. Putting this knowledge and our results together, we believe that elderly people with impaired pulmonary function would greatly benefit from attentive pulse palpation by healthcare providers as well as from self-palpation.

Undiagnosed AF is common, and opportunistic screening for silent AF is likely to be cost-effective in the elderly $[9,25]$. The screening of older populations yielded a prevalence of $2.3 \%$ for chronic forms of AF [26]. In the present study, the prevalence of IP was only $2.6 \%$. This finding is consistent with the low prevalence of AF in the general population in Korea. In a healthy, asymptomatic rural Korean population, the prevalence of ECG-diagnosed AF was only 2.3\% among 60- and 70-year-olds [27]. Since subjects with paroxysmal AF may be classified as having an RP, pulse palpation may only be able to screen those with persistent or permanent AF.

COPD is usually diagnosed using PFT; FEV1/FVC $<70 \%$ confirms the presence of persistent airflow limitation and thus of COPD [28]. The worldwide prevalence of COPD is estimated to be $3-11 \%$ [29]. However, the prevalence of history of COPD in the present study was just $1 \%$. Therefore, the prevalence of COPD as assessed by PFT was higher than that determined from the patient responses on the questionnaires. This suggests that many subjects in this study might have undiagnosed COPD. Yoo et al. showed a similar trend, reporting that despite the high prevalence of COPD in Korea, the disease is underdiagnosed, and most COPD patients are under-treated [30].

\section{Limitations}

This study has a few limitations. First, there were no available ECG data to confirm the presence or absence of arrhythmias and, if present, to verify the type of arrhythmia. Elderly subjects are susceptible to a wide range of different cardiac arrhythmias, many of which may be associated with radial pulse irregularities. Nonetheless, the aim of our study was to assess if there was any association between IP and reduced pulmonary function in the elderly but not to correlate IP with a real arrhythmia. Second, there were no data about the period of discontinuation of smoking in ex-smokers or the exact prevalence of cardiomyopathy or thyroid disease, which might have an influence on pulmonary function or the prevalence of arrhythmia, respectively. Lastly, although there was no significant difference in the 
percentage of participants taking antihypertensive medications between the two groups, there were no detailed data about specific types of antihypertensive drugs such as beta-blocker and calcium-channel blocker that could also have had some influence on pulse regularity. Despite the presence of some limitations, we believe that this study is significant, as no previous study has described the association between pulmonary function and IP identified by pulse palpation in the general population.

\section{Conclusions}

Our study showed that the elderly with reduced pulmonary function were more likely to have an irregular radial pulse than those with normal pulmonary function. This finding suggests that pulse palpation may be a good screening tool for cardiac arrhythmia in older adults with reduced pulmonary function. Healthcare providers, especially nurses and physician assistants, should pay close attention to assessing for the presence or absence of IPs and monitor for arrhythmias in older patients with reduced pulmonary function. Further studies will be necessary to determine if subjects $<65$ years of age with reduced pulmonary function also have an irregular radial pulse more often than those with normal pulmonary function.

Author Contributions: Conceptualization, writing-original draft, and formal analysis, S.H.K. and J.-K.P.; investigation and supervision, Y.L., S.Y.H., J.S. and C.K.K.; methodology and software, S.H.K., Y.L. and S.Y.H.; resources and data curation, J.S., C.K.K. and J.-K.P.; funding acquisition, J.-K.P. All authors have read and agreed to the published version of the manuscript.

Funding: This research was funded by the National Research Foundation of Korea grant funded by the Korean government (MSIT; Ministry of Science) (No. 2019R1F1A1046443).

Acknowledgments: We thank the Korean Center for Disease Control and Prevention, which carried out the KNHANES, and all the participants in the present study for their generous cooperation.

Conflicts of Interest: The authors declare no conflict of interest.

\section{References}

1. January, C.T.; Wann, L.S.; Alpert, J.S.; Calkins, H.; Cigarroa, J.E.; Cleveland, J.C., Jr.; Conti, J.B.; Ellinor, P.T.; Ezekowitz, M.D.; Field, M.E.; et al. 2014 AHA/ACC/HRS guideline for the management of patients with atrial fibrillation: A report of the American College of Cardiology/American Heart Association Task Force on Practice Guidelines and the Heart Rhythm Society. J. Am. Coll. Cardiol. 2014, 64, e1-e76. [CrossRef] [PubMed]

2. Soliman, E.Z.; Safford, M.M.; Muntner, P.; Khodneva, Y.; Dawood, F.Z.; Zakai, N.A.; Thacker, E.L.; Judd, S.; Howard, V.J.; Howard, G.; et al. Atrial fibrillation and the risk of myocardial infarction. JAMA Intern. Med. 2014, 174, 107-114. [CrossRef] [PubMed]

3. Mozaffarian, D.; Benjamin, E.J.; Go, A.S.; Arnett, D.K.; Blaha, M.J.; Cushman, M.; de Ferranti, S.; Després, J.P.; Fullerton, H.J.; Howard, V.J.; et al. Heart disease and stroke statistics-2015 update: A report from the American Heart Association. Circulation 2015, 131, e29-e322. [CrossRef] [PubMed]

4. Shea, J.B.; Sears, S.F. Cardiology patient pages. A patient's guide to living with atrial fibrillation. Circulation 2008, 117, e340. [CrossRef]

5. Cooke, G.; Doust, J.; Sanders, S. Is pulse palpation helpful in detecting atrial fibrillation? A systematic review. J. Fam. Pract. 2006, 55, 130-134.

6. Virtanen, R.; Kryssi, V.; Vasankari, T.; Salminen, M.; Kivelä, S.L.; Airaksinen, K.E. Self-detection of atrial fibrillation in an aged population: The LietoAF Study. Eur. J. Prev. Cardiol. 2014, 21, 1437-1442. [CrossRef]

7. Kirchhof, P.; Benussi, S.; Kotecha, D.; Ahlsson, A.; Atar, D.; Casadei, B.; Castella, M.; Diener, H.C.; Heidbuchel, H.; Hendriks, J.; et al. 2016 ESC Guidelines for the management of atrial fibrillation developed in collaboration with EACTS. Eur. Heart J. 2016, 37, 2893-2962. [CrossRef]

8. Pérula-de-Torres, L.; Martínez-Adell, M.; González-Blanco, V.; Baena-Díez, J.M.; Martín-Rioboó, E.; Parras-Rejano, J.M.; González-Lama, J.; Martín-Alvarez, R.; Ruiz-Moral, R.; Fernández-García, J.; et al. Opportunistic detection of atrial fibrillation in subjects aged 65 years or older in primare care: A randomised clinical trial of efficacy. DOFA-AP study protocol. BMC Fam. Pract. 2012, 13, 106. [CrossRef] 
9. Hobbs, F.D.; Fitzmaurice, D.A.; Mant, J.; Murray, E.; Jowett, S.; Bryan, S.; Raftery, J.; Davies, M.; Lip, G. A randomised controlled trial and cost-effectiveness study of systematic screening (targeted and total population screening) versus routine practice for the detection of atrial fibrillation in people aged 65 and over. The SAFE study. Health Technol. Assess 2005, 9, 1-74. [CrossRef]

10. Fitzmaurice, D.A.; Hobbs, F.D.; Jowett, S.; Mant, J.; Murray, E.T.; Holder, R.; Raftery, J.P.; Bryan, S.; Davies, M.; Lip, G.Y.; et al. Screening versus routine practice in detection of atrial fibrillation in patients aged 65 or over: Cluster randomised controlled trial. BMJ 2007, 335, 383. [CrossRef]

11. Ryu, J.H.; Krowka, M.J.; Pellikka, P.A.; Swanson, K.L.; McGoon, M.D. Pulmonary hypertension in patients with interstitial lung diseases. Mayo Clin. Proc. 2007, 82, 342-350. [CrossRef]

12. Sideris, D.A.; Katsadoros, D.P.; Valianos, G.; Assioura, A. Type of cardiac dysrhythmias in respiratory failure. Am. Heart J. 1975, 89, 32-35. [CrossRef]

13. Kim, B.S.; Park, J.-K.; Lee, Y.; Shin, J.H.; Lim, Y.-H.; Park, H.-C.; Kim, C.K.; Shin, J. The relationship between decreased pulmonary function and atrial fibrillation in general population: Findings from Ansung-Ansan cohort of the Korean Genome and Epidemiology Study. J. Cardiol. 2019, 74, 488-493. [CrossRef] [PubMed]

14. Buch, P.; Friberg, J.; Scharling, H.; Lange, P.; Prescott, E. Reduced lung function and risk of atrial fibrillation in the Copenhagen City Heart Study. Eur. Respir. J. 2003, 21, 1012-1016. [CrossRef] [PubMed]

15. Kweon, S.; Kim, Y.; Jang, M.J.; Kim, Y.; Kim, K.; Choi, S.; Chun, C.; Khang, Y.H.; Oh, K. Data resource profile: The Korea National Health and Nutrition Examination Survey (KNHANES). Int. J. Epidemiol. 2014, 43, 69-77. [CrossRef]

16. Pellegrino, R.; Viegi, G.; Brusasco, V.; Crapo, R.O.; Burgos, F.; Casaburi, R.; Coates, A.; van der Grinten, C.P.; Gustafsson, P.; Hankinson, J.; et al. Interpretative strategies for lung function tests. Eur. Respir. J. 2005, 26, 948-968. [CrossRef]

17. Lee, J.; Reyes, B.A.; McManus, D.D.; Maitas, O.; Chon, K.H. Atrial fibrillation detection using an iPhone 4S. IEEE Trans. Biomed. Eng. 2013, 60, 203-206. [CrossRef]

18. McManus, D.D.; Lee, J.; Maitas, O.; Esa, N.; Pidikiti, R.; Carlucci, A.; Harrington, J.; Mick, E.; Chon, K.H. A novel application for the detection of an irregular pulse using an iPhone $4 \mathrm{~S}$ in patients with atrial fibrillation. Heart Rhythm. 2013, 10, 315-319. [CrossRef]

19. Dagher, L.; Shi, H.; Zhao, Y.; Marrouche, N.F. Wearables in cardiology: Here to stay. Heart Rhythm. 2020, 17, 889-895. [CrossRef]

20. Li, J.; Agarwal, S.K.; Alonso, A.; Blecker, S.; Chamberlain, A.M.; London, S.J.; Loehr, L.R.; McNeill, A.M.; Poole, C.; Soliman, E.Z.; et al. Airflow obstruction, lung function, and incidence of atrial fibrillation: The Atherosclerosis Risk in Communities (ARIC) study. Circulation 2014, 129, 971-980. [CrossRef]

21. Johnson, L.S.; Juhlin, T.; Engström, G.; Nilsson, P.M. Reduced forced expiratory volume is associated with increased incidence of atrial fibrillation: The Malmo Preventive Project. Europace 2014, 16, 182-188. [CrossRef] [PubMed]

22. Kim, Y.G.; Han, K.-D.; Choi, J.-I.; Boo, K.Y.; Kim, D.Y.; Lee, K.-N.; Shim, J.; Kim, J.S.; Kim, Y.-H. Frequent drinking is a more important risk factor for new-onset atrial fibrillation than binge drinking: A nationwide population-based study. Europace 2020, 22, 216-224. [CrossRef] [PubMed]

23. Kallmünzer, B.; Bobinger, T.; Kahl, N.; Kopp, M.; Kurka, N.; Hilz, M.J.; Marquardt, L.; Schwab, S.; Köhrmann, M. Peripheral pulse measurement after ischemic stroke: A feasibility study. Neurology 2014, 83, 598-603. [CrossRef]

24. January, C.T.; Wann, L.S.; Calkins, H.; Chen, L.Y.; Cigarroa, J.E.; Cleveland, J.C.; Ellinor, P.T.; Ezekowitz, M.D.; Field, M.E.; Furie, K.L. 2019 AHA/ACC/HRS focused update of the 2014 AHA/ACC/HRS guideline for the management of patients with atrial fibrillation: A report of the American College of Cardiology/American Heart Association Task Force on Clinical Practice Guidelines and the Heart Rhythm Society. J. Am. Coll. Cardiol. 2019, 74, 104-132. [CrossRef] [PubMed]

25. Davis, R.C.; Hobbs, F.D.; Kenkre, J.E.; Roalfe, A.K.; Iles, R.; Lip, G.Y.; Davies, M.K. Prevalence of atrial fibrillation in the general population and in high-risk groups: The ECHOES study. Europace 2012, 14, 1553-1559. [CrossRef]

26. Lowres, N.; Neubeck, L.; Redfern, J.; Freedman, S.B. Screening to identify unknown atrial fibrillation. A systematic review. Thromb. Haemost. 2013, 110, 213-222. [CrossRef] 
27. Park, H.C.; Park, J.K.; Choi, S.I.; Kim, S.G.; Kim, M.K.; Choi, B.Y.; Shin, J. Prevalence of atrial fibrillation and relation to echocardiographic parameters in a healthy asymptomatic rural Korean Population. J. Korean Med. Sci. 2015, 30, 1078-1084. [CrossRef]

28. Vestbo, J.; Hurd, S.S.; Agustí, A.G.; Jones, P.W.; Vogelmeier, C.; Anzueto, A.; Barnes, P.J.; Fabbri, L.M.; Martinez, F.J.; Nishimura, M.; et al. Global strategy for the diagnosis, management, and prevention of chronic obstructive pulmonary disease: GOLD executive summary. Am. J. Respir. Crit. Care Med. 2013, 187, 347-365. [CrossRef]

29. Buist, A.S.; McBurnie, M.A.; Vollmer, W.M.; Gillespie, S.; Burney, P.; Mannino, D.M.; Menezes, A.M.; Sullivan, S.D.; Lee, T.A.; Weiss, K.B.; et al. International variation in the prevalence of COPD (the BOLD Study): A population-based prevalence study. Lancet 2007, 370, 741-750. [CrossRef]

30. Yoo, K.H.; Kim, Y.S.; Sheen, S.S.; Park, J.H.; Hwang, Y.I.; Kim, S.H.; Yoon, H.I.; Lim, S.C.; Park, J.Y.; Park, S.J.; et al. Prevalence of chronic obstructive pulmonary disease in Korea: The fourth Korean National Health and Nutrition Examination Survey, 2008. Respirology 2011, 16, 659-665. [CrossRef]

(C) 2020 by the authors. Licensee MDPI, Basel, Switzerland. This article is an open access article distributed under the terms and conditions of the Creative Commons Attribution (CC BY) license (http://creativecommons.org/licenses/by/4.0/). 